\title{
Limitation of thermogravimetry for oxy-combustion analysis of coal chars
}

\author{
Piotr Babinski $^{1}$ (D) $\cdot$ Marek Sciazko $^{1} \cdot$ Ewelina Ksepko $^{1}$
}

Received: 6 July 2017/ Accepted: 24 October 2017/Published online: 9 November 2017

(c) The Author(s) 2017. This article is an open access publication

\begin{abstract}
A kinetic study of the oxy-combustion of chars obtained from two Polish steam coals was conducted. A comparative study was focused on the data analysis concerning oxy-combustion of coal chars collected from two thermobalances, which differed in construction, design of crucibles, sample size and gas flow direction. The influence of individual factors such as temperature, $\mathrm{O}_{2}$ concentration, the dimensions of the crucibles and the dimensions of the char bed on the reaction rate was analysed. On the basis of these results, a global kinetic model was elaborated showing the influence of all factors, particularly mass transfer conditions, on reaction rates. The developed model can be extended to other mass transfer conditions or fluidised bed conditions and can be applied to other fast reactions to ensure they occur in the chemical reaction kinetics control regime during TG tests. It was concluded that the gas-solid fuel contact characteristics are crucial for the measured reaction rate and for the interpretation of kinetic data.
\end{abstract}

Keywords Diffusion effects - Kinetics · Oxy-combustion · Char combustion

\section{Abbreviations \\ APTGA Atmospheric pressure thermogravimetric analyser \\ HPTGA High-pressure thermogravimetric analyser}

Piotr Babinski

pbabinski@ichpw.pl

1 Institute for Chemical Processing of Coal, 1 Zamkowa, 41-803 Zabrze, Poland

\author{
List of symbols \\ A $\quad$ Surface $/ \mathrm{m}^{2}$ \\ $A_{0} \quad$ Pre-exponential factor/s $\mathrm{s}^{-1}$ \\ AC Ash content $/$ mass\% \\ C Concentration of gas $/ \mathrm{mol} \mathrm{m}^{-3}$ \\ d Diameter $/ \mathrm{m}$ \\ $D \quad$ Diffusion coefficient $/ \mathrm{m}^{2} \mathrm{~s}^{-1}$ \\ $E_{\mathrm{a}} \quad$ Activation energy $/ \mathrm{kJ} \mathrm{mol}^{-1}$ \\ $h \quad$ Height $/ \mathrm{m}$ \\ $k_{\mathrm{D}} \quad$ Mass transfer coefficient $/ \mathrm{m} \mathrm{s}^{-1}$ \\ $l \quad$ Length $/ \mathrm{m}$ \\ LHV Lower heating value/ $\mathrm{J} \mathrm{g}^{-1}$ \\ $m \quad$ Mass/mg \\ $M \quad$ Moisture content/mass\% \\ $N \quad$ Molar flow rate of gas $/ \mathrm{mol} \mathrm{s}^{-1}$ \\ $P \quad$ Pressure \\ $r \quad$ Reaction/diffusion $\mathrm{rate} / \mathrm{mol} \mathrm{s}^{-1}$ \\ $R \quad$ Universal gas constant $/ \mathrm{kJ} \mathrm{mol}^{-1} \mathrm{~K}^{-1}$ \\ $R_{\mathrm{p}} \quad$ Pore radius $/ \mathrm{m}$ \\ Re Reynolds number/- \\ $S \quad$ Specific surface area $/ \mathrm{m}^{2} \mathrm{~g}^{-1}$ \\ Sh Sherwood number/- \\ Sc Schmidt number/- \\ $T$ Temperature/K \\ $t \quad$ Time/s \\ $u \quad$ Velocity of gas $/ \mathrm{m} \mathrm{s}^{-1}$ \\ $V \quad$ Volatile matter content $/$ mass\% \\ $X \quad$ Conversion degree of solid/- \\ $y \quad$ Molar fraction/- \\ $\beta \quad$ Heating rate/K $\min ^{-1}$ \\ $\mu \quad$ Viscosity/Pa s \\ $\rho \quad$ Density $/ \mathrm{kg} \mathrm{m}^{-3}$ \\ $\tau_{\mathrm{p}} \quad$ Tortuosity of the pores/- \\ $\varepsilon_{0} \quad$ Porosity of the particle/-
}




\section{Subscripts \\ ash Relates to mineral matter \\ b Refers to bed \\ BET Brunner-Emmett-Teller \\ $\mathrm{CO}_{2}$ Related to carbon dioxide \\ con Refers to convection \\ D Refers to diffusion/mass transport \\ D-A Dubinin-Astachow \\ eff Effective \\ ext Refers to external \\ g Refers to gas \\ int Refers to internal \\ K Refers to Knudsen diffusion \\ N Refers to crucible \\ me Refers to mesopores \\ mi Refers to micropores \\ $\mathrm{O}_{2} \quad$ Related to oxygen \\ obs Observed \\ $\mathrm{R} \quad$ Refers to reaction \\ t Total \\ $0 \quad$ Refers to initial state}

\section{Superscripts}

$\begin{array}{ll}\text { ar } & \text { As-received basis } \\ \text { ad } & \text { Air-dried basis } \\ \text { d } & \text { Dry basis } \\ \text { daf } & \text { Dry and ash-free basis }\end{array}$

\section{Introduction}

Recently, great attention has been focused on carbon dioxide emissions from the power sector due to the significant impact of the greenhouse effect. To reduce the emissions of greenhouse gases from fossil fuel-fired power generation, the oxy-combustion of coal seems to be a promising future technology combined with retrofitting of existing boilers to allow an $\mathrm{O}_{2}$-enriched atmosphere for combustion $[1,2]$.

In the process of oxy-combustion of fossil fuels, a high purity of oxygen (above 95\%) and a stream of recycled $\mathrm{CO}_{2}$ from the flue gas are used to control the combustion temperature. The process product is a gas consisting mostly of $\mathrm{CO}_{2}$ and water vapour. The considerable concentration of $\mathrm{CO}_{2}$ in the gas enables direct referral to sequestration, which is followed by condensation of water vapour [3, 4].

The oxy-combustion process comprises several consecutive processes and reactions. When a coal particle is introduced into the combustion chamber of a fluidised bed, it is heated with a high heating rate (up to $1000 \mathrm{~K} \mathrm{~s}^{-1}$ ). This step involves drying and pyrolysis of the coal particle, and the evolution of volatile matter consisting of combustible gases, while char is produced. The volatiles burn in homogenous reactions, and the char reacts with oxygen (heterogeneous reaction). The reaction of carbon from char with $\mathrm{O}_{2}$ is the slowest step of the whole process [5-7]. Therefore, the present work focuses on the coal char oxycombustion, because its reaction rate is crucial for boiler design. Since the oxy-combustion of coal char is a heterogeneous reaction, it can proceed under three different reaction-controlling regimes: chemical kinetics, mixed internal diffusion-chemical kinetics and external diffusion $[8,9]$. Oxy-combustion in a fluidised bed boiler occurs at a temperature of $1073-1173 \mathrm{~K}$ where diffusion limitations exist $[3,4,10]$. The scaling-up of this process requires an extensive computational analysis, which is critical for proper boiler design. Herein, a kinetic analysis is fundamental for oxy-combustion process modelling, where the kinetic equations are implemented using modelling software.

On the other hand, thermogravimetric analysis is a commonly used technique to investigate the kinetics of fast heterogeneous reactions such as the combustion of solid fuels, the oxidation of oxygen carriers [5, 6, 11-19]. It is well known that kinetic parameters should be obtained under a chemical reaction-controlling regime $[5,6,13,14,17-19]$, which is important for the study of oxy-combustion kinetics.

Some researchers have proposed specific approaches to finding the transport limitations in TGs during combustion or gasification of fuels $[11,12,20]$. They have found a number of parameters which are crucial for shifting the regime from chemical kinetics to diffusion, especially crucibles and their dimensions, fuel bed mass and gas flow direction. The interpretation of these results involves a numerical analysis which is difficult to apply to other cases.

The aim of the paper is the identification of diffusional limitations for the crucibles used in thermobalances, which influence the kinetic analysis of fast reactions, such as, for example, oxy-combustion. As a result of the study, suitable and generalised models for oxygen transport to the coal char particles in $\mathrm{TG}$ crucibles were developed. Moreover, the models can be extended for application in fluidised bed processes.

\section{Experimental}

\section{Sample properties}

Two char samples obtained from Polish lignite (Turów) and hard coal (Janina), which are extensively used for combustion in Polish power plants, were investigated. The chars were prepared using a laboratory stand for the pyrolysis of solid fuels. First, ca $150 \mathrm{~g}$ of coal sample of 
size $1-3.15 \mathrm{~mm}$ was placed in a cylindrical batch reactor. The reactor was heated up to $1273 \mathrm{~K}$ at a heating rate of $5 \mathrm{~K} \mathrm{~min}^{-1}$ under nitrogen. Subsequently, the reactor was flushed with $\mathrm{N}_{2}$ to cool the sample to room temperature. The coal sample and obtained char samples were crushed and sieved to a particle size smaller than $200 \mu \mathrm{m}$ and were further analysed.

The proximate analyses of the coal and char samples were performed by a gravimetric method using a LECO TGA701 analyser. The ultimate analysis that followed sulphur analysis was conducted using CHN TruSpec LECO and LECO SC632 apparatus. Pore structure was analysed by nitrogen adsorption at $77 \mathrm{~K}$ and $\mathrm{CO}_{2}$ adsorption at $273 \mathrm{~K}$, using Micromeritics 3Flex apparatus. A Malvern Instruments Mastersizer 2000 particle analyser with a dispersion Hydro 2000G mouthpiece was used for analysing the particle size distribution of coal chars.

The tested samples were significantly different in terms of metamorphism degree, as indicated by the volatile content, elemental composition of coals and particularly the oxygen content (Table 1). The pyrolysis of coal led to an increase in elemental C content to approx. $80 \%$ and to the reduction of the hydrogen, oxygen, sulphur and nitrogen contents. The analysis results obtained from the coal chars indicate that the chemical compositions of the chars are similar, even though they come from coals with a different degree of metamorphism. The pyrolysis resulted mainly in the removal of moisture from the coal samples, and in a separation of the volatile components, producing lignite char with zero content, and approximately $0.5 \%$ for hard coal char. In other words, the pyrolysis of the coal has increased the degree of metamorphism of the parent coals and conformed them chemically to one another. Although the technical and chemical analyses show that the properties of chars are similar, there are some significant differences in their structure. This has the greatest impact on the char particles' reactivity. For example, the pore structure of the char has a greater impact than its chemical composition. A smaller specific surface area (determined by the BET method), of the order of few $\mathrm{m}^{2} \mathrm{~g}^{-1}$, is shown by the sample of hard coal char and a significantly larger surface area by the lignite char. The surface area of the micropores, determined by adsorption of $\mathrm{CO}_{2}$ at $273 \mathrm{~K}$, confirmed the greater surface area of the lignite char micropores (Table 2).

\section{Thermogravimetric analysis}

Oxy-combustion tests were conducted in two thermobalances, namely an atmospheric pressure Netzsch STA 409 PG Luxx (APTGA) thermobalance, and a TA Instrument pressurised thermobalance TG-HP150 s with Rubotherm magnetic suspension balance (HPTGA). The dimensions of the TGA's furnace and crucibles, and also the experimental
Table 1 Proximate and ultimate analyses of coal

\begin{tabular}{lrc}
\hline & Lignite & Hard coal \\
\hline Proximate analysis & & \\
$M^{\mathrm{ar}} / \%$ & 44.20 & 21.30 \\
$M^{\mathrm{a}} / \%$ & 3.90 & 12.40 \\
$\mathrm{AC} / \%$ & 7.80 & 10.40 \\
$V^{\mathrm{daf}} / \%$ & 59.14 & 39.56 \\
$\mathrm{LHV}^{\mathrm{a}} / \mathrm{MJ} \mathrm{kg}^{-1}$ & 24.72 & 22.84 \\
$\mathrm{Ultimate} \mathrm{analysis}^{\mathrm{a}} / \%$ & & \\
$H^{\mathrm{a}} / \%$ & 62.30 & 60.40 \\
$N^{\mathrm{a}} / \%$ & 5.48 & 3.46 \\
$S_{\mathrm{t}}^{\mathrm{a}} \%$ & 0.61 & 0.94 \\
$O^{\mathrm{a}} / \%$ & 1.02 & 1.22 \\
\hline
\end{tabular}

Table 2 Proximate and ultimate analyses of coal chars

\begin{tabular}{lcc}
\hline & Lignite char & Hard coal char \\
\hline Proximate analysis & & \\
$M^{\mathrm{a}} / \%$ & 0.20 & 0.70 \\
$A^{\mathrm{a}} / \%$ & 12.32 & 15.19 \\
$V^{\mathrm{daf}} / \%$ & 0.00 & 0.54 \\
$\mathrm{Ultimate}$ analysis & & \\
$C^{\mathrm{a}} / \%$ & 82.50 & 81.40 \\
$H^{\mathrm{a}} / \%$ & 0.34 & 0.35 \\
$N^{\mathrm{a}} / \%$ & 1.06 & 0.99 \\
$S_{\mathrm{t}}^{\mathrm{a}} / \%$ & 0.93 & 0.65 \\
$O^{\mathrm{a}} / \%$ & 2.85 & 1.42 \\
$\mathrm{~N}_{2} \mathrm{adsorption}$ at $77 \mathrm{~K}$ & & \\
$S_{\mathrm{BET}} / \mathrm{m}^{2} \mathrm{~g}^{-1}$ & 17.3 & 3.8 \\
$V_{\mathrm{t}} / \mathrm{cm}^{3} \mathrm{~g}^{-1}$ & 0.0154 & 0.0448 \\
$V_{\mathrm{mi}} / \mathrm{cm}^{3} \mathrm{~g}^{-1}$ & 0.0091 & 0.0011 \\
$V_{\mathrm{me}} / \mathrm{cm}^{3} \mathrm{~g}^{-1}$ & 0.0063 & 0.0438 \\
$\mathrm{CO}_{2} \mathrm{adsorption}$ at $273 \mathrm{~K}$ & & \\
$S_{\mathrm{D}-\mathrm{A}} / \mathrm{m}^{2} \mathrm{~g}^{-1}$ & 719.31 & 0.0322 \\
$V_{\mathrm{t}} / \mathrm{cm}^{3} \mathrm{~g}^{-1}$ & 0.2055 & \\
\hline
\end{tabular}

conditions, differ in these two thermobalances. The differences are presented in Tables 3 and 4.

The reaction furnaces of the two TGAs in which the crucibles are placed are of the tubular type. For each of the thermobalances, a specific method of crucible mounting is applied. In the APTGA, the crucible is placed on a long rod which is a carrier for the crucible and is connected to the mass measuring system placed below the reaction furnace. On the other hand, HPTGA has a completely different type of crucible mounting. In this case, the crucible is suspended 
Table 3 Properties of the crucibles

\begin{tabular}{|c|c|c|}
\hline & $\begin{array}{l}\text { Thermobalance } \\
\text { Netzsch } 409 \text { PG } \\
\text { Luxx }\end{array}$ & $\begin{array}{l}\text { Pressurised } \\
\text { thermobalance } \\
\text { TA TG-HP150 s }\end{array}$ \\
\hline Furnace diameter, $d_{\mathrm{R}} / \mathrm{mm}$ & 22.0 & 23.0 \\
\hline $\begin{array}{l}\text { Cross-sectional area of the } \\
\text { reactor, } A_{\mathrm{N}} / \mathrm{mm}^{2}\end{array}$ & 380.1 & 415.5 \\
\hline Crucible diameter, $d_{\mathrm{N}} / \mathrm{mm}$ & 5.9 & 10.0 \\
\hline $\begin{array}{l}\text { Cross-sectional area of the } \\
\text { crucible (area of the char } \\
\text { layer), } A_{\mathrm{N}} / \mathrm{mm}^{2}\end{array}$ & 27.3 & 78.5 \\
\hline Height of the crucible, $h_{\mathrm{n}} / \mathrm{mm}$ & 3.9 & 25.0 \\
\hline Sample mass, $m_{0} / \mathrm{mg}$ & 5.0 & 10.0 \\
\hline $\begin{array}{l}\text { Total gas flow rate, } \\
\dot{V} / \mathrm{cm}^{3} \min ^{-1}\end{array}$ & 125 & 1000 \\
\hline $\begin{array}{l}\text { Flow rate of } \mathrm{O}_{2} \\
\dot{V} / \mathrm{cm}^{3} \mathrm{~min}^{-1}\end{array}$ & 20 & 200 \\
\hline
\end{tabular}

Table 4 Properties of the sample bed

\begin{tabular}{lllll}
\hline & $\begin{array}{l}\text { Lignite } \\
\text { char } \\
\text { APTGA }\end{array}$ & $\begin{array}{l}\text { Hard coal } \\
\text { char } \\
\text { APTGA }\end{array}$ & $\begin{array}{l}\text { Lignite } \\
\text { char } \\
\text { HPTGA }\end{array}$ & $\begin{array}{l}\text { Hard coal } \\
\text { char } \\
\text { HPTGA }\end{array}$ \\
\hline $\begin{array}{c}\text { Height of the char } \\
\text { layer, } h_{\mathrm{b}} / \mathrm{mm}\end{array}$ & 257.6 & 215.2 & 179.3 & 149.8 \\
$\begin{array}{c}\text { Mean char particle } \\
\text { diameter, } d_{\mathrm{p} / \mathrm{mm}}\end{array}$ & 225.2 & 172.5 & 225.2 & 172.5 \\
$\begin{array}{c}\text { Ratio of char bed } \\
\text { height to particle } \\
\text { diameter, } h_{\mathrm{b}} / d_{\mathrm{p}}\end{array}$ & 1.14 & 1.25 & 0.80 & 0.87 \\
\hline
\end{tabular}

on a weighing hook which is connected to the permanent magnet (magnetic roller) of the upper part of the reactor. The permanent magnet is maintained by a magnetic field from an electromagnet, which is a part of the electronic measuring system of the balance. Gas entering the APTGA is introduced at the bottom of the furnace and flows upwards washing the crucible. Therefore, the gas cannot interfere with the stationary gas layer in the crucible in any way. In the case of the HPTGA, the gas is introduced into the upper part of the furnace and it flows vertically downwards. Therefore, the gas could influence the gas layer in the crucible. In Tables 3 and 4, the dimensions of the individual furnaces of the thermobalances are shown together with dimensions of the crucibles used. The gas flow values and the properties of the char beds are also included.

The experiments were conducted at isothermal conditions by applying the temperature of 450 (only for the lignite char), 500, 550, 600, 700, 800, 900 and $1000{ }^{\circ} \mathrm{C}$. In the APTGA an alumina crucible was used, and in the HPTGA a quartz crucible with porous bottom was used. Reaction gases with defined composition and specific volume flow were fed into the reaction furnace. The gaseous mixtures with a suitable molar fraction of oxygen $y_{\mathrm{O}_{2}}$ in $\mathrm{CO}_{2}$ equal to 0.2 were introduced into both TGAs. Moreover, a protecting gas of ca $25 \mathrm{~N} \mathrm{~cm}^{3} \min ^{-1}$ of $\mathrm{Ar}$ was dosed into the APTGA. For APTGA the char sample mass was $m_{0}=5 \mathrm{mg}$, while for HPTGA it was $10 \mathrm{mg}$. Comparison of the flow conditions showed that the flow rate of the gas through the furnace was approximately eight times higher for HPTGA than it was for APTGA. All these parameters could have a significant effect on the results obtained from the thermogravimetric analysis.

Analysing the presented data, it can be concluded that the height of the char bed in both cases is comparable to the diameter of the particles. Therefore, considering the properties of the char bed it can be assumed that it is a monolayer of particles, almost evenly distributed at the bottom of the crucible. In addition, the ratio of the char bed diameter to its height is very large: for the lignite char and hard coal char for the APTGA crucible, it amounts to 22.9 and 27.4, respectively. The corresponding values for the HPTGA case are 55.8 and 66.8. For this reason, it can be assumed that the char bed is a single char tablet with height $h_{\mathrm{b}}$. The crucible diameter is designated $d_{\mathrm{N}}$, and the crosssectional area (footprint) is $A_{\mathrm{N}}$. This assumption is used to describe the reaction rate in crucibles for both thermobalances.

\section{Results and discussion}

\section{Model development}

After the initial coal pyrolysis stage, the combustion of coal chars proceeds in several consecutive and parallel processes. Inside a real industrial boiler, a single particle is raised in the reacting gases flowing upwards and is surrounded by a laminar gas layer, as shown in Fig. 1a. Oxygen from the bulk gas enters the laminar layer surrounding the char particle by convection, and then the $\mathrm{O}_{2}$ transport occurs by diffusion. Therefore, the process can be divided into several stages as follows:

- $\mathrm{O}_{2}$ transport to the particle and within the particle, which consists of:

- $\mathrm{O}_{2}$ convection to the gas film surrounding the char particle,

- $\mathrm{O}_{2}$ diffusion in the laminar gas layer surrounding the particle,

- $\mathrm{O}_{2}$ diffusion in the pores of the char particle. 
(a)

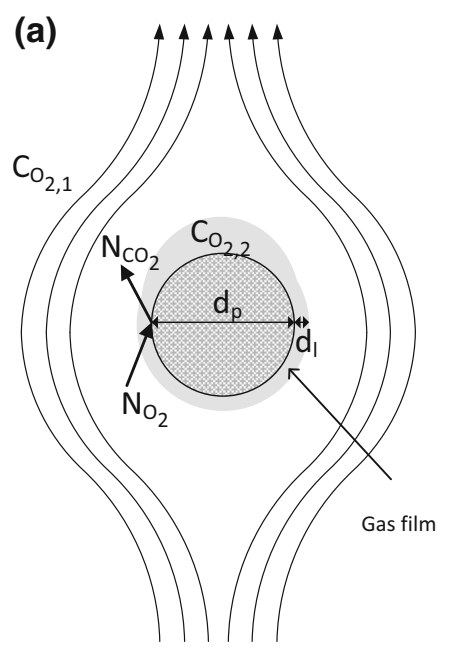

(b)

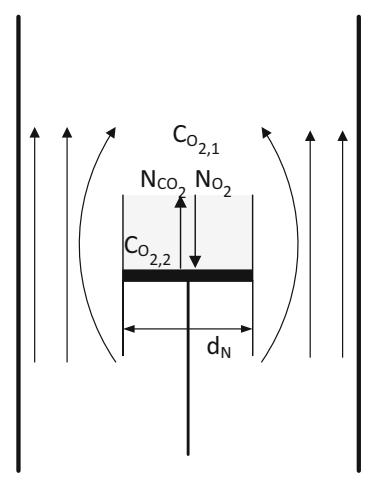

(c)

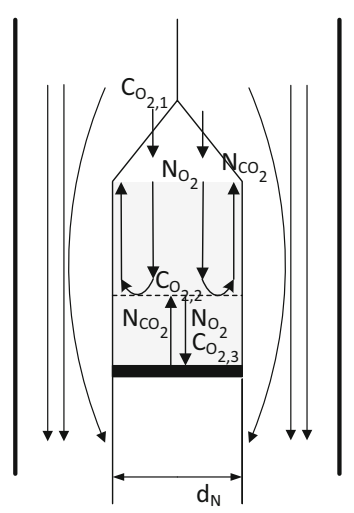

Fig. 1 Model approach of $\mathrm{O}_{2}$ transport: a fluidised bed, b APTGA, c HPTGA

- A chemical reaction on the internal surface of the char particle.

In the TGA, char particles are not carried in the gas but they form a fixed bed of thickness $h_{\mathrm{b}}$ at the bottom of the crucible. The mass transfer differs from that in the fluidised bed, which may affect the oxy-combustion reaction rate. Figure 1 shows schematically the flow patterns in the fluidised bed and in the crucibles used in TGA.

The overall oxy-combustion reaction rate is a result of all existing resistances, and it can be shown as Eq. (1):

$\frac{1}{r_{\mathrm{obs}}}=\frac{1}{r_{\mathrm{R}}}+\frac{1}{r_{\mathrm{D}}}$

where $r_{\mathrm{obs}}$ is the observed overall reaction rate, $r_{\mathrm{R}}$ is the chemical reaction rate, and $r_{\mathrm{D}}$ is the $\mathrm{O}_{2}$ transport rate.

In the chemical kinetic regime, the chemical reaction is the slowest step of global reaction, and the main rate-determining step is a chemical reaction rate. Thus, the condition $r_{\mathrm{obs}}=r_{\mathrm{R}}$ is valid, and the reaction can be described using $n$ th-order kinetics as in Eq. (2):

$r_{\mathrm{obs}}=r_{\mathrm{R}}=k_{\mathrm{R}} \cdot f(X) \cdot C_{\mathrm{O}_{2}}^{n}$

where $k_{\mathrm{R}}$ is a chemical reaction constant, $C_{\mathrm{O}_{2}}$ is the $\mathrm{O}_{2}$ concentration on the surface of the char particle (in the kinetic regime on both the inner and outer surface of particle), $n$ is the reaction order with respect to $\mathrm{O}_{2}$ concentration, and $f(X)$ represents the reaction model.

The reaction rate in this analysis is represented as the rate of $\mathrm{C}$ element loss from the char in moles, in a specified time interval, i.e. $\mathrm{d} N_{\mathrm{C}} / \mathrm{d} t$ as calculated from Eq. (3):

$r=\frac{\mathrm{d} N_{\mathrm{C}}}{\mathrm{d} t}=\frac{\mathrm{d} m}{\mathrm{~d} t} \frac{1}{M_{\mathrm{C}}}, \mathrm{mol} \mathrm{s}^{-1}$

where $d m / d t$ is the reaction rate from DTG and $M_{\mathrm{C}}$ is the molar mass of carbon $\left(12 \mathrm{~g} \mathrm{~mol}^{-1}\right)$.
The mean value of the reaction rate from a conversion range of $0.2-0.8$ was used in this paper, and only one concentration of oxygen was applied. Therefore, the reaction model $f(X)$ and the $\mathrm{O}_{2}$ concentration are both included in the reaction rate constant which is equal to the reaction rate $\left(r_{\mathrm{R}}=k_{\mathrm{R}}\right)$. The Arrhenius equation is shown in Eq. (4):

$\ln \left(r_{\mathrm{R}}\right)=\frac{-E_{\mathrm{a}}}{R \cdot T}+\ln \left(A_{0}\right)$

where $E_{\mathrm{a}}$ is the activation energy and $A_{0}$ is a pre-exponential factor.

With increasing temperature, the main resistance to the reaction may be $\mathrm{O}_{2}$ transport to the char particle surface (diffusion regime). In these conditions, when the temperature is increased, the reaction rate is not significantly increased, because of the small increase in $\mathrm{O}_{2}$ transport rate. Therefore, the overall reaction rate may be equal to the rate of $\mathrm{O}_{2}$ transport, or in other words $r_{\mathrm{obs}}=r_{\mathrm{D}}$. Therefore, specific $\mathrm{O}_{2}$ transport models can be applied for different apparatus and for different types of solid-gas contact.

\section{The transport model of $\mathrm{O}_{2}$ in the APTGA crucible}

In the APTGA crucible, the gas flows vertically upwards and it flows around the crucible. Subsequently, it joins the uniform gas flow which takes place over the crucible. Figure 2 shows a schematic representation of the APTGA crucible, with the directions of reactant transportation and their local concentrations indicated (Fig. 2a). The potential distribution of the $\mathrm{O}_{2}$ concentration as a function of crucible height is shown in Fig. 2b.

At the top of the crucible, the $\mathrm{O}_{2}$ concentration is the same as in the bulk gas and is equal to the initial concentration of $\mathrm{O}_{2}$ directed to the furnace, $C_{\mathrm{O}_{2}, 1}$. In the crucible 
Fig. 2 Model approach of $\mathrm{O}_{2}$ transport in the crucible of the APTGA thermobalance:

a schematic with selected concentrations and the molar fraction of $\mathrm{O}_{2}$, with dimensions and directions of flow of the reactants, $\mathbf{b}$ distribution of $\mathrm{O}_{2}$ concentration as a function of crucible height
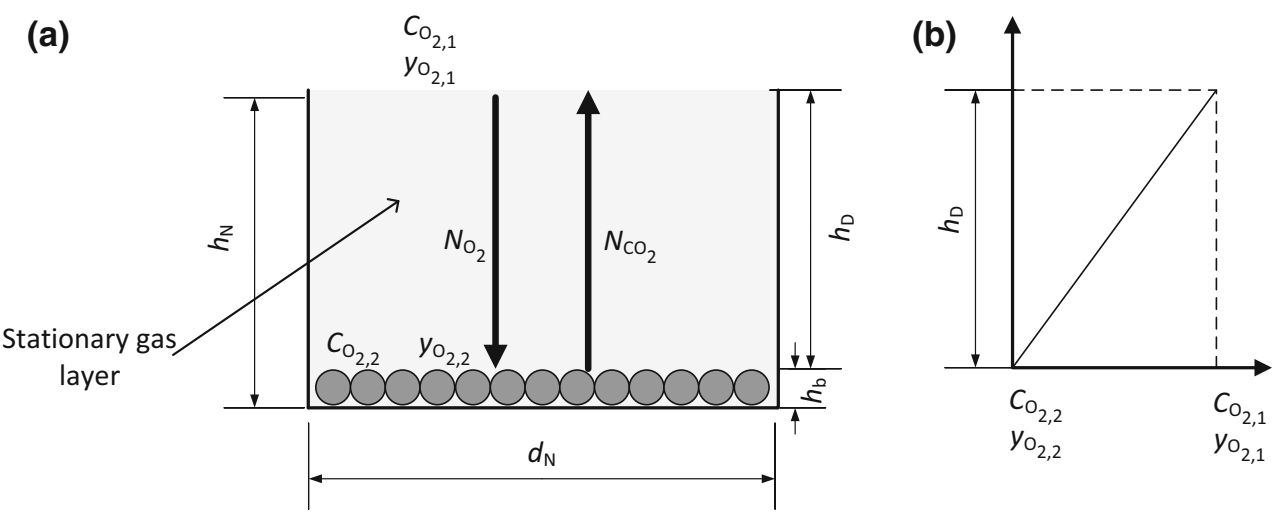

above the bed of char considered as a tablet, there is a stationary layer of gas with height $h_{\mathrm{D}}$ equal to the height of the crucible $h_{\mathrm{N}}$ minus the thickness of the char layer $h_{\mathrm{b}}$. When oxy-combustion of the char takes place, the concentration of $\mathrm{O}_{2}$ on the surface of the char bed, $C_{\mathrm{O}_{2}, 2}$, decreases as a result of the reaction. Combustion of one mole of $\mathrm{O}_{2}$ results in the formation of one mole of $\mathrm{CO}_{2}$. Therefore, for each mole of $\mathrm{O}_{2}$ flowing towards the particle there is one mole of $\mathrm{CO}_{2}$ which diffuses in the opposite direction, as described by Eq. (5):

$\dot{N}_{\mathrm{O}_{2}}=\dot{N}_{\mathrm{CO}_{2}}, \mathrm{~mol} \mathrm{~s}^{-1}$

Fick's first law defines the equimolar countercurrent diffusion rate, which is proportional to the concentration gradients of the components and inversely proportional to the length of the diffusion path which is the height of stationary gas layer. As a consequence, for $\mathrm{O}_{2}$ diffusion, it can be mathematically expressed as in Eq. (6) [18]:

$\dot{N}_{\mathrm{O}_{2}}=D_{\mathrm{O}_{2}} \frac{d C_{\mathrm{O}_{2}}}{d h_{\mathrm{D}}}, \mathrm{mol} \mathrm{m}^{-2} \mathrm{~s}^{-1}$

where $\mathrm{d}_{\mathrm{O}_{2}}$ is the $\mathrm{O}_{2}$ concentration gradient between two points along the length of the diffusion path $\mathrm{d} h_{\mathrm{D}}$ and $D_{\mathrm{O}_{2}}$ is the molecular diffusion coefficient of $\mathrm{CO}_{2}$ in $\mathrm{O}_{2}$.

After separation of variables, integration and taking into consideration the surface of the char bed (the crucible area), this is modified as follows:

$\dot{N}_{\mathrm{O}_{2}}=\frac{D_{\mathrm{O}_{2}}}{h_{\mathrm{D}}} A_{\mathrm{N}}\left(C_{\mathrm{O}_{2}, 1}-C_{\mathrm{O}_{2}, 2}\right), \mathrm{mol} \mathrm{s}^{-1}$

where $A_{\mathrm{N}}$ is the surface of the char bed in the crucible calculated according to the equation $A_{\mathrm{N}}=\pi \cdot d_{\mathrm{N}}^{2} / 4$.

The molecular diffusion coefficient is dependent on both the temperature and the pressure value, and it can be calculated from the Fuller-Schettler-Giddings equation shown as Eq. (8) [18]:
$D_{\mathrm{O}_{2}}=\frac{9.86 \times 10^{-5}}{\left(v_{\mathrm{O}_{2}}^{1 / 3}+v_{\mathrm{CO}_{2}}^{1 / 3}\right)} \sqrt{\left(\frac{1}{M_{\mathrm{O}_{2}}}+\frac{1}{M_{\mathrm{CO}_{2}}}\right)} \cdot \frac{T^{1.75}}{P_{\mathrm{t}}}, \mathrm{m}^{2} \mathrm{~s}^{-1}$

where $v_{\mathrm{O}_{2}}$ and $v_{\mathrm{CO}_{2}}$ are the molar volumes of both gas components, (i.e. $\mathrm{O}_{2}$ and $\mathrm{CO}_{2}$ ), $M_{\mathrm{O}_{2}}$ and $M_{\mathrm{CO}_{2}}$ are the molar masses of $\mathrm{O}_{2}$ and $\mathrm{CO}_{2}, P_{\mathrm{t}}$ is the total pressure, and $T$ is the temperature.

There are also other mathematical relations enabling calculation of the molecular diffusion coefficient, and these are widely shown elsewhere [21]. The molecular diffusion coefficient is a parameter which is characteristic for the set of two gases, and it is independent of the components' concentrations. As can be seen, the diffusion coefficient is proportional to the temperature to the power of 1.75 and inversely proportional to the total pressure. As a result, it can be concluded that the reaction steps of oxy-combustion in the reported TGA system are:

- $\mathrm{O}_{2}$ diffusion in a stationary gas layer in accordance with Fick's first law (from the inlet of the crucible to the surface of the char bed).

- Chemical reaction on the surface of char particles.

The slower of the two above stages will be the ratelimiting step. In the extreme case where the global rate of the reaction is determined by the rate of $\mathrm{O}_{2}$ diffusion in the crucible, the concentration of $\mathrm{O}_{2}$ on the surface of the char bed will be $C_{\mathrm{O}_{2}, 2}=0$. This means that the diffusion resistance of $\mathrm{O}_{2}$ between the inlet of the measuring crucible and the surface of the char bed is the largest. Each oxygen molecule diffusing to the bed surface will immediately react when it makes contact with the nearest carbon atom. Therefore, the model of diffusion in the crucible can be simplified to Eq. (9):

$\dot{N}_{\mathrm{O}_{2}}=\frac{D_{\mathrm{O}_{2}}}{h_{\mathrm{D}}} A_{\mathrm{N}} C_{\mathrm{O}_{2}, 1}, \mathrm{~mol} \mathrm{~s}^{-1}$ 


\section{Oxygen transportation model in the HPTGA crucible}

The gas flow in the pressurised thermogravimetric analyser (HPTGA) is directed downwards, resulting in interference with the gas layer in the crucible (Fig. 1c). Furthermore, the crucible has a porous semipermeable bottom, which might result in some partial gas flow throughout the crucible.

In Fig. 3 the schematic of the crucible from the HPTGA is shown. The directions of reactant transportation and their local concentrations, together with the potential distribution of the $\mathrm{O}_{2}$ concentration as a function of the height of the crucible, are shown for the established convectiondiffusion model.

There are two gas layers in the crucible: convection (turbulent gas layer) and diffusion (stationary gas layer). In the upper layer with height $h_{\text {con }}$, the gas flowing into the crucible can cause turbulence and hence transport of oxygen by convection. In the bottom part of the crucible, there is a gas diffusion layer at the char bed surface with height $h_{\mathrm{D}}$, where the transport of $\mathrm{O}_{2}$ takes place by equimolar countercurrent diffusion, in accordance with Fick's first law [21]. Therefore, the steps of the oxy-combustion reaction in the analysed HPTGA system are:
- Transport of $\mathrm{O}_{2}$ to the mouth of the crucible.

- Convection of $\mathrm{O}_{2}$ to the surface of the diffusion layer.

- Diffusion of $\mathrm{O}_{2}$ through a stationary gas layer in accordance with Fick's first law.

- Chemical reaction on the surface of the char.

Assuming that the transport of $\mathrm{O}_{2}$ in the convection zone is carried out over the height of $h_{\text {con }}$ to the planar surface of $A_{\mathrm{N}}$, the transport rate of $\mathrm{O}_{2}$ is represented by Eq. (10) [21]:

$\dot{N}_{\mathrm{O}_{2}}=k_{\mathrm{D}, \mathrm{O}_{2}} A_{\mathrm{N}}\left(C_{\mathrm{O}_{2}, 1}-C_{\mathrm{O}_{2}, 2}\right), \mathrm{mol} \mathrm{s}^{-1}$

where $k_{\mathrm{D}, \mathrm{O}_{2}}$ is the $\mathrm{O}_{2}$ transfer coefficient.

The term $k_{\mathrm{D}, \mathrm{O}_{2}}$, which is a mass transfer coefficient for the flat surface, may be defined by Eq. (11), [18]:

$k_{\mathrm{D}, \mathrm{O}_{2}}=\frac{D_{\mathrm{O}_{2}} S h}{L}=\frac{D_{\mathrm{O}_{2}} S h}{d_{\mathrm{N}}}$

where $L$ is the length of the surface on which the penetration of mass is followed (in this work the model presented is the diameter of the crucible $d_{\mathrm{N}}$ ), $S h$ is the Sherwood number, $R e$ is the Reynolds number, and $S c$ is the Schmidt number.

Sherwood's number for $\mathrm{O}_{2}$ transport to the flat surface is calculated from Eq. (12) [18]:

$S h=0.664 R e^{1 / 2} S c^{1 / 3}$

while the Reynolds number is calculated from Eq. (13):
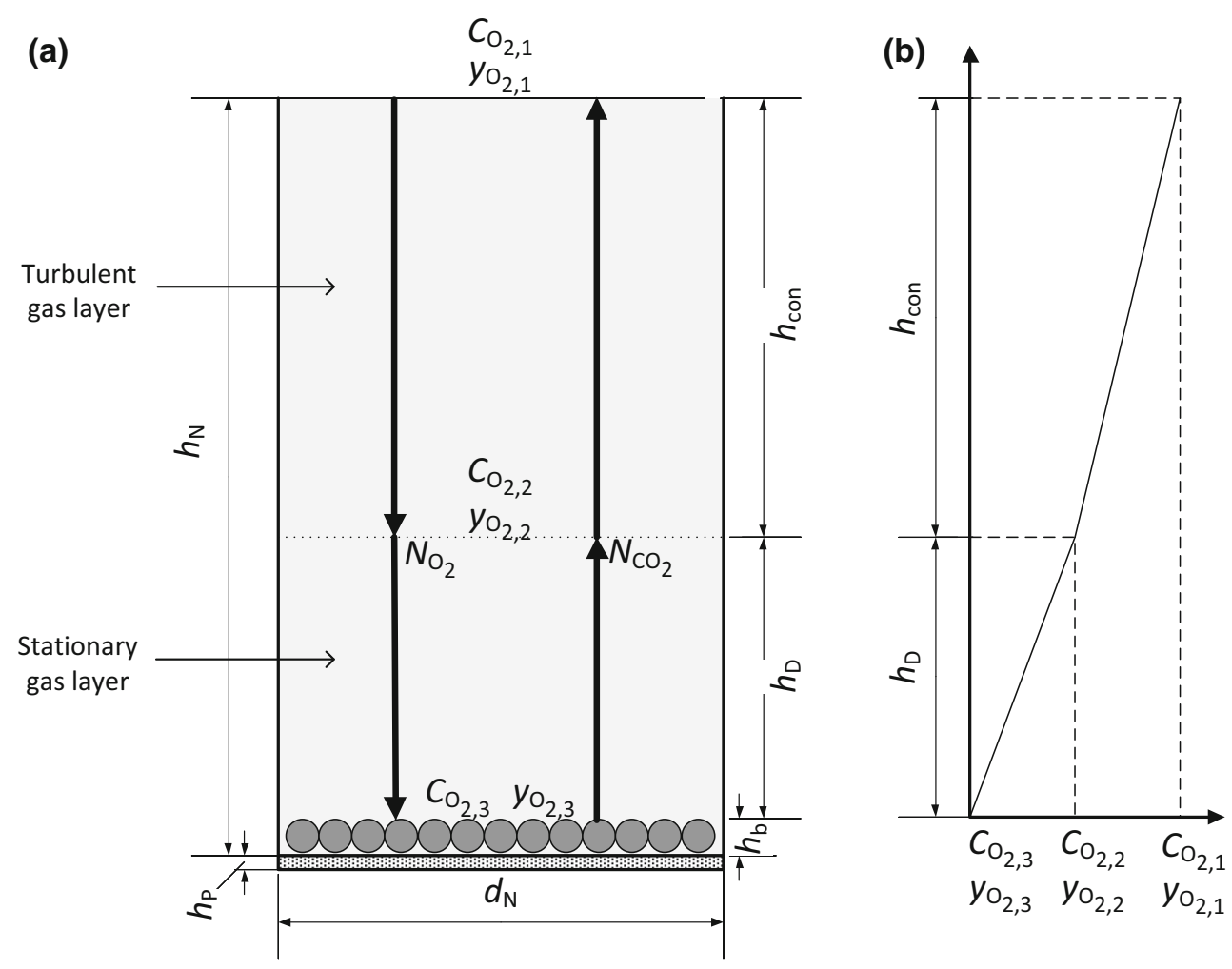

Fig. 3 Model approach of $\mathrm{O}_{2}$ transport in the crucible of the HPTGA: a schematic with selected concentrations and molar fractions of $\mathrm{O}_{2}$, with dimensions and directions of flow of the reactants, $\mathbf{b}$ distribution of $\mathrm{O}_{2}$ concentration as a function of crucible height 
$R e=\frac{d_{N} u_{g} \rho_{g}}{\mu_{g}}$

where $u_{\mathrm{g}}$ is the rate of gas entering the crucible, $\mu_{\mathrm{g}}$ is the viscosity of the gas, and $\rho_{\mathrm{g}}$ is the gas density.

The Schmidt number is calculated from Eq. (14):

$S c=\frac{\mu_{\mathrm{g}}}{\rho_{\mathrm{g}} D_{\mathrm{O}_{2}}}$

Above the surface of the char bed is a layer of stationary gas with height $h_{\mathrm{D}}$, where the transport of $\mathrm{O}_{2}$ occurs by equimolecular countercurrent diffusion, in accordance with Fick's first law. This is expressed by the relation described in Eq. (15):

$\dot{N}_{\mathrm{O}_{2}}=\frac{D_{\mathrm{O}_{2}}}{h_{\mathrm{D}}} A_{\mathrm{N}}\left(C_{\mathrm{O}_{2}, 2}-C_{\mathrm{O}_{2}, 3}\right), \mathrm{mol} \mathrm{s}^{-1}$

Since the oxy-combustion reaction is faster than the transport rate of $\mathrm{O}_{2}$, on the surface of the char bed, the concentration of $\mathrm{O}_{2}\left(C_{\mathrm{O}_{2}, 3}\right)$ is close to zero and is therefore negligible with respect to further calculations. As a consequence, Eq. (15) can be simplified to Eq. (16):

$\dot{N}_{\mathrm{O}_{2}}=\frac{D_{\mathrm{O}_{2}}}{h_{\mathrm{D}}} A_{N} C_{\mathrm{O}_{2}, 2}, \mathrm{~mol} \mathrm{~s}^{-1}$

Calculating the flow rate of $\mathrm{O}_{2}$ in the HPTGA crucible is problematic because there are some unknown factors, such as the heights of the convection and diffusion layers from Eq. (8) and Eq. (14), respectively. The concentration of $\mathrm{O}_{2}$ at the interface between the two layers $C_{\mathrm{O}_{2}, 2}$ is also unknown. Assuming that conditions are stationary, the transport rate of $\mathrm{O}_{2}$ in the convective layer must be equal to the diffusion rate of $\mathrm{O}_{2}$ in the stationary gas layer. Therefore, Eq. (10) and Eq. (16) are related by Eq. (17):

$\dot{N}_{\mathrm{O}_{2}}=k_{\mathrm{D}, \mathrm{O}_{2}} A_{\mathrm{N}}\left(C_{\mathrm{O}_{2}, 1}-C_{\mathrm{O}_{2}, 2}\right)=\frac{D_{\mathrm{O}_{2}}}{h_{\mathrm{D}}} A_{\mathrm{N}} C_{\mathrm{O}_{2}, 2}$

After simplifying and substituting for $k_{\mathrm{D}, \mathrm{O}_{2}}$ from Eq. (16), Eq. (18) is obtained:

$\dot{N}_{\mathrm{O}_{2}}=\frac{D_{\mathrm{O}_{2}} S h}{d_{\mathrm{N}}}\left(C_{\mathrm{O}_{2}, 1}-C_{\mathrm{O}_{2}, 2}\right)=\frac{D_{\mathrm{O}_{2}}}{h_{\mathrm{D}}} C_{\mathrm{O}_{2}, 2}$

However, the concentration of $\mathrm{O}_{2}$ at the interface between these two gas layers is still not known. Hence, a further assumption is made, i.e. that $\mathrm{O}_{2}$ transport resistance in the convection layer and $\mathrm{O}_{2}$ diffusion in the stationary gas layer are equal. This means that the differences in concentrations in both layers are equal, and this condition can be written in the form of Eq. (19):

$C_{\mathrm{O}_{2}, 1}-C_{\mathrm{O}_{2}, 2}=C_{\mathrm{O}_{2}, 2}=\frac{C_{\mathrm{O}_{2}, 1}}{2}$

Simplifying Eq. (18) and substituting it into Eq. (17) lead to Eq. (20):
$h_{\mathrm{D}}=\frac{d_{\mathrm{N}}}{S h}$

Furthermore, substituting Eq. (19) and Eq. (20) into Eq. (16), the equation for transport rate of $\mathrm{O}_{2}$ through the whole crucible in HPTGA is obtained:

$\dot{N}_{\mathrm{O}_{2}}=\frac{S h \cdot D_{\mathrm{O}_{2}}}{d_{\mathrm{N}}} A_{\mathrm{N}} \frac{C_{\mathrm{O}_{2}, 1}}{2}, \mathrm{~mol} \mathrm{~s}^{-1}$

This association allows the calculation of the $\mathrm{O}_{2}$ stream in the HPTGA crucible, and it also indirectly enables calculation of the thickness of the diffusion convection layers.

\section{Analysis of experimental data}

The developed $\mathrm{O}_{2}$ transport models in the crucibles have been applied to the analysis of the experimental data from oxy-combustion of coal char using both TGAs. The aim of this study was to demonstrate that the differences in the obtained results can be explained by the difference in the effective rate of $\mathrm{O}_{2}$ transport to the surface of the char bed. Figures 4 and 5 show the reaction rate curves $r=\mathrm{d} N_{\mathrm{C}} /$ $\mathrm{d} t$ as a function of conversion for the oxy-combustion
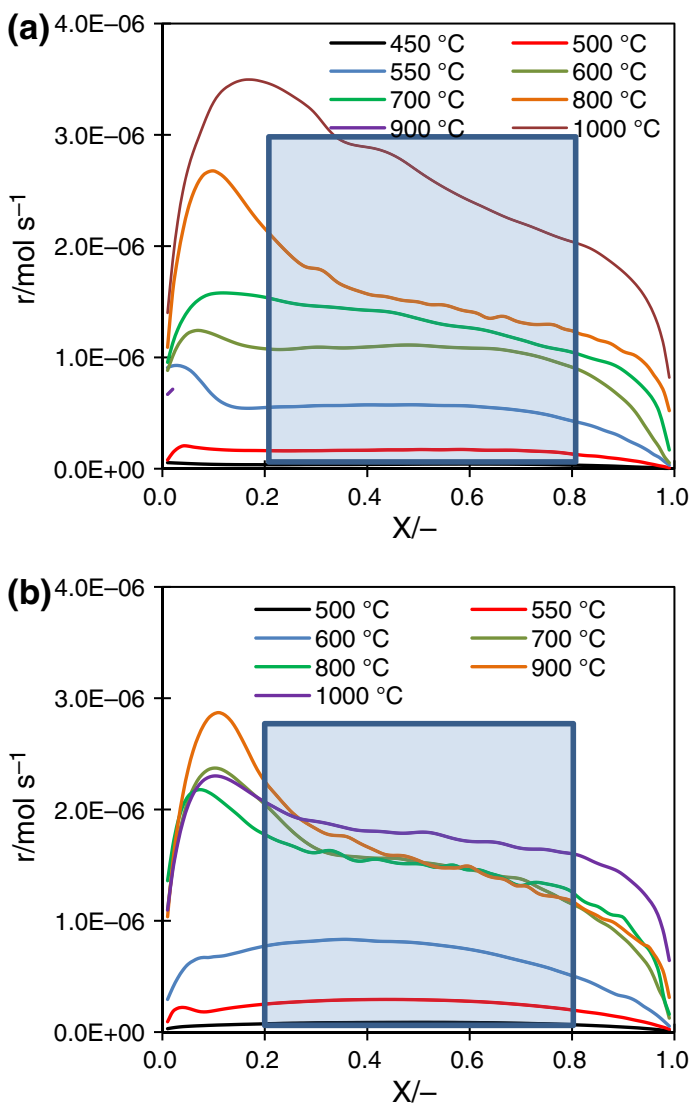

Fig. 4 Reaction rate versus $X$ for oxy-combustion of: a lignite char and $\mathbf{b}$ hard coal char, obtained in the APTGA 

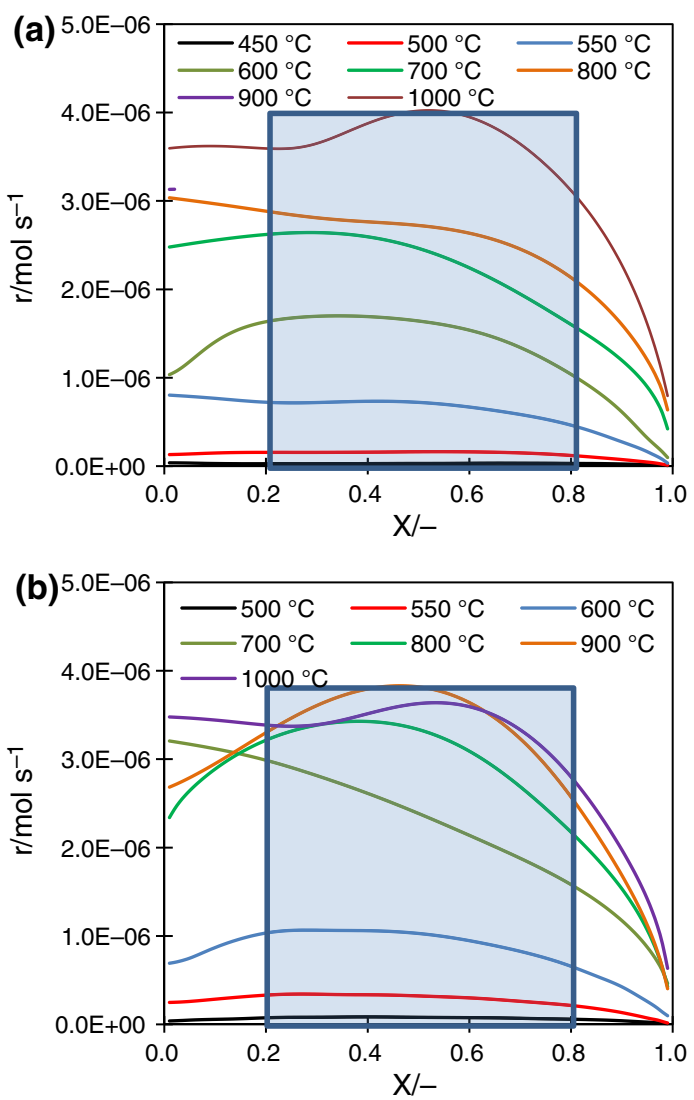

Fig. 5 Reaction rate versus $X$ for oxy-combustion of: a lignite char and $\mathbf{b}$ hard coal char, obtained in the HPTGA

experiments from the APTGA and HPTGA thermobalances respectively.

The presented data indicate a significant increase in the reaction rate up to a temperature of approximately $600{ }^{\circ} \mathrm{C}$, after which the reaction rate progression is less significant. Comparing the oxy-combustion of the investigated two chars, it can be concluded that the reaction proceeds at a higher rate for lignite char which has the higher BET surface area $\left(17.3 \mathrm{~m}^{2} \mathrm{~g}^{-1}\right)$ compared to hard coal char with lower surface area $\left(3.8 \mathrm{~m}^{2} \mathrm{~g}^{-1}\right)$. Another aspect of this analysis is also extremely important, i.e. the clear difference between the reaction rates obtained depending upon the measuring apparatus used. Higher reaction rates are achieved in HPTGA than are obtained in APTGA.

For the calculation of the reaction rates, the mean value of the reaction rates with a conversion ratio of $0.2-0.8$ was used. This range is indicated as a blue field in Figs. 4 and 5 . The range of conversion degree is characterised by the smallest changes in the reaction rate, and it can be considered as representative for further analysis.

Figure 6 presents a comparison of the experimental data with the results of the model analysis for both TGs. Analysing the data, it can be seen that in the low-temperature range (up to $550{ }^{\circ} \mathrm{C}$ for lignite char and up to $600{ }^{\circ} \mathrm{C}$ for
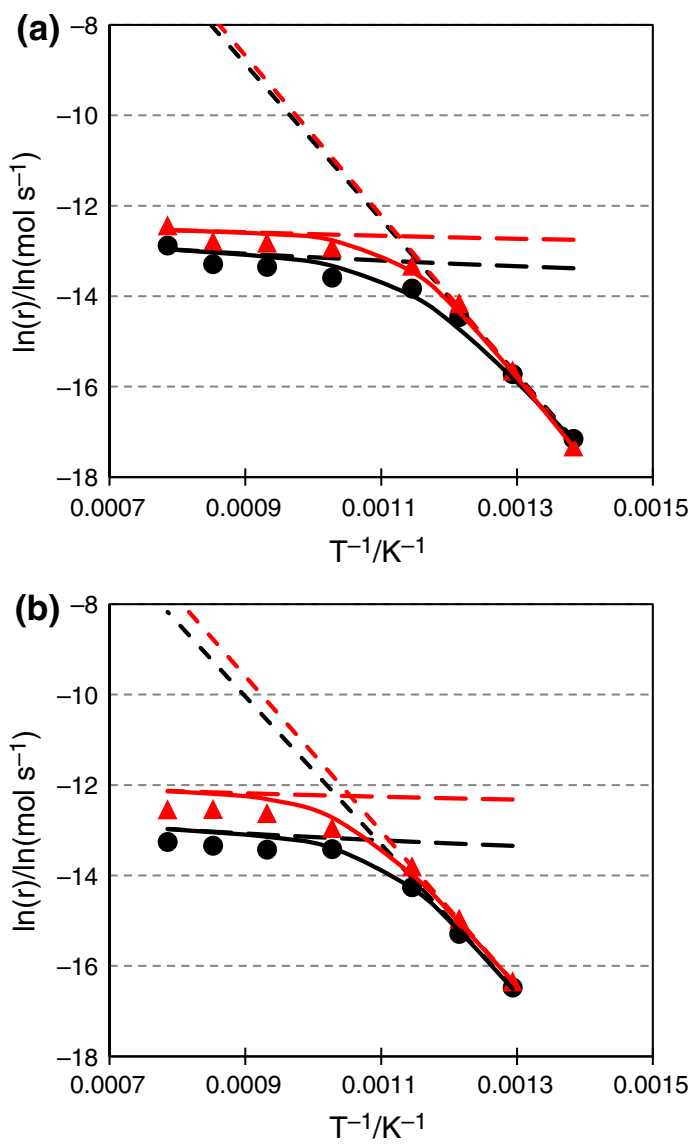

Fig. 6 Arrhenius plots for the oxy-combustion of: a lignite char and b hard coal char: black colour-APTGA; red colour-HPTGA; dashed line, chemical reaction rate; long dashed line, $\mathrm{O}_{2}$ transport rate in the crucible; solid line, the overall reaction rate; filled circle, APTGA experimental value; filled triangle, HPTGA experimental value

hard coal char) the reaction rate increases significantly, followed by a slowdown of the reaction rate above these temperatures. Under low-temperature experimental conditions, the chemical reaction kinetics is the rate-limiting step which determines the overall reaction rate. With increasing temperature (greater than $550{ }^{\circ} \mathrm{C}$ for lignite char and greater than $600{ }^{\circ} \mathrm{C}$ for hard coal char), the diffusion rate of $\mathrm{O}_{2}$ in the crucibles becomes the main resistance, and $\mathrm{O}_{2}$ transport is the rate-limiting step. To confirm this thesis, the results of the model analysis and the experimental results are compared, as shown for both TGs in Fig. 6a, b.

In Fig. 6 the model data for the oxy-combustion chemical reaction are shown extrapolated up to a temperature of $1000{ }^{\circ} \mathrm{C}$. The extrapolation of the results was based on data obtained from the estimation of kinetic parameters using Eq. 4. Data from the $450-550{ }^{\circ} \mathrm{C}$ range for the lignite char and from the $500-600{ }^{\circ} \mathrm{C}$ range for hard coal char were used to estimate the kinetic parameters of chemical reactions in the kinetic regime, i.e. the activation 
energy $E_{\mathrm{a}}$ and the exponential coefficient $A_{0}$. These parameters were used to calculate the rate of oxy-combustion chemical reaction up to $1000{ }^{\circ} \mathrm{C}$ where the ratedetermining step above approximately $600{ }^{\circ} \mathrm{C}$ is the extrapolated value. The results of the kinetic parameter estimates are presented in Table 5.

As can be seen, the results from both thermobalances correlate with each other at a very high level, with correlation coefficients above 0.99. As a result, the following values were obtained for lignite and hard coal chars, respectively:

$$
\begin{aligned}
E_{\mathrm{a}} & =145 \mathrm{~kJ} \mathrm{~mol}^{-1} \text { with } \ln \left(A_{0}\right) \\
& =6.87 \ln \left(\mathrm{mol} \mathrm{s}^{-1}\right), \text { and } E_{\mathrm{a}} \\
& =134 \mathrm{~kJ} \mathrm{~mol}^{-1}, \text { with } \ln \left(A_{0}\right)=4.38 \ln \left(\mathrm{mol} \mathrm{s}^{-1}\right) .
\end{aligned}
$$

Figure 6 presents the results of the $\mathrm{O}_{2}$ transport rate models in the crucible in accordance with Fick's first law for APTGA and a mixed convection-diffusion model for HPTGA. The overall observed reaction rate for oxy-combustion in the crucible from TGA is the sum of the chemical reaction resistance and the $\mathrm{O}_{2}$ transport resistance in the crucible, and it can be represented by the previously shown Eq. (1).

The presented model analysis indicates the very significant impact of the crucibles and the type of balance used on the reaction rate for coal chars. Among other things, this includes the type of crucible and its dimensions, and the direction of the reaction gas flow which is crucial for the type of gas-solid fuel contact. The results of the analysis are essential for the correct interpretation of the results obtained from oxy-combustion experiments using TG. They allow for clear distinction between the impact of the coal char properties on the reaction rate from the influence of the crucible and the apparatus conditions in which the measurement is performed. At temperatures higher than $600{ }^{\circ} \mathrm{C}$, the oxy-combustion reaction rate is mainly influenced by the measuring apparatus, and also the shape and dimensions of the experimental crucible. The latter factor is responsible for the shifting of oxy-combustion to the diffusion regime. This conclusion gives rise to the comparison of the results obtained from the two TG instruments.
The analysis evidently shows that in the kinetic regime the differences between TGAs are negligible. The obtained reaction rates do not significantly differ, and therefore, the results of the experimental studies in the two different apparatuses are comparable with each other. This means that if adequate working TGA conditions are maintained for the reaction in the kinetic regime, the experimental results should lead to similar reaction rates. However, in the mass transfer-limiting regime the experimental results primarily depend on the apparatus in which they were obtained. Hence, in this regime the apparatus and its specification mainly determine the reaction rate.

In the thermogravimetric analysis, char particles are deposited as a bed in the TG's crucible. Therefore, there is no way for gas to wash each particle separately as it does in a fluidised bed, which has key implications for the kinetic analysis of oxy-combustion. In a boiler, char particles formed after the pyrolysis of coal are carried in the gas stream. Therefore, there are no limitations on the type and depth of the measuring vessel (crucible) affecting the $\mathrm{O}_{2}$ transport rate. Under such conditions, the model of char oxy-combustion, and in particular the oxygen transport rate model, must be modified. The transport rate of $\mathrm{O}_{2}$ to the surface of the char particle, assuming that on the particle surface the $C_{\mathrm{O}_{2}, 2}$ concentration is zero, is expressed by Eq. (22):

$r_{\mathrm{D}, \mathrm{O}_{2}}=\dot{N}_{\mathrm{O}_{2}}=k_{\mathrm{D}, \mathrm{O}_{2}} A_{\mathrm{p}} C_{\mathrm{O}_{2}, 1}, \mathrm{~mol} \mathrm{~s}^{-1}$

where $k_{\mathrm{D}, \mathrm{O}_{2}}$ is the $\mathrm{O}_{2}$ transport rate constant over the surface of the char particle.

For particles raised in a gas stream, the $\mathrm{O}_{2}$ transport rate coefficient is calculated from Froessling's equation $[5,6,9,18,19,21,22]$. For particles with a spherical geometry, this is expressed as follows:

$S h=\frac{k_{\mathrm{ext}, \mathrm{O}_{2}} d_{\mathrm{p}}}{D_{\mathrm{O}_{2}}}=2.0+0.6 R e_{\mathrm{p}}^{1 / 2} S c^{1 / 3}$

where $d_{\mathrm{p}}$ is the char particle diameter.

The existence of internal diffusion causes a consequent resistance of both internal and external diffusion which is different from the external resistance itself. A resultant

\begin{tabular}{|c|c|c|c|c|c|c|}
\hline & \multicolumn{3}{|c|}{$\begin{array}{l}\text { Lignite char } \\
\text { Data set: } 450-550{ }^{\circ} \mathrm{C}\end{array}$} & \multicolumn{3}{|c|}{$\begin{array}{l}\text { Hard coal char } \\
\text { Data set: } 500-600{ }^{\circ} \mathrm{C}\end{array}$} \\
\hline & APTGA & HPTGA & Mean value & APTGA & HPTGA & Mean value \\
\hline$E_{\mathrm{a}} / \mathrm{kJ} \mathrm{mol}^{-1}$ & 143 & 147 & 145 & 136 & 142 & 139 \\
\hline $\ln \left(A_{0}\right) / \ln \left(\mathrm{mol} \mathrm{s}^{-1}\right)$ & 6.57 & 7.23 & 6.88 & 4.66 & 5.83 & 5.23 \\
\hline$R^{2}$ & 1.00 & 0.99 & - & 0.99 & 0.99 & - \\
\hline
\end{tabular}
resistance can be calculated from Eq. (24):

Table 5 Estimation of kinetic parameters for chemical kinetic controlling regime 
$k_{\mathrm{D}, \mathrm{O}_{2}}=\left(\frac{1}{k_{\mathrm{int}, \mathrm{O}_{2}}}+\frac{1}{k_{\mathrm{ext}, \mathrm{O}_{2}}}\right)^{-1}$

where the internal diffusion rate constant is determined using Eq. (25):

$k_{\mathrm{int}, \mathrm{O}_{2}}=\frac{D_{\text {eff }, \text { int }}}{2 \cdot R_{\mathrm{p}}}$

where $D_{\text {eff,int }}$ is the effective diffusion coefficient for $\mathrm{O}_{2}$ in the char particle pores and $R_{\mathrm{p}}$ is the pore radius.

The diffusion coefficient in the pores refers to single pores; therefore, for the purpose of generalisation to the whole porous particle, the following relationship is used:

$D_{\text {eff }, \text { int }}=\frac{D_{\text {int }} \varepsilon_{0}}{\tau_{\mathrm{p}}}$

where $\tau_{\mathrm{p}}$ is the tortuosity of the pores and $\varepsilon_{0}$ is the porosity of the particle.

Generally, it can be assumed that the pore diffusion rate is in the transition area and is dependent on Knudsen diffusion as well as on molecular diffusion [5-9, 21-23]. Therefore, the diffusion coefficient in the pores is calculated from Eq. (27):

$\frac{1}{D_{\text {int }}}=\frac{1}{D_{\mathrm{O}_{2}}}+\frac{1}{D_{\mathrm{K}}}$

where $D_{\mathrm{K}}$ is the Knudsen diffusion coefficient and $D_{\text {int }}$ is the diffusion coefficient in the pores.

The internal rate of diffusion constant indirectly determines the effect of particle size on the chemical reaction rate, and essentially, it replaces the efficiency factor which is determined by the Thiele modulus. This relationship allows the calculation of internal diffusion resistance independently of the kinetics of the chemical reaction, as is the case for Thiele modulus calculations. Table 6 presents the specific values of the gas diffusion parameters in pores and dimensionless numbers for both chars.

Hard coal char has a lower diffusional limit because of the lower porosity and specific surface area which results in higher Knudsen diffusion coefficient values and finally higher diffusion coefficients in the pores. Reynolds numbers are higher for the lignite char particles because of the higher particle diameter, resulting in a higher Sherwood number.

The results of the model analysis which show the comparison of the conditions of HPTGA with a fluidised bed boiler are presented in Fig. 7.

For fluidised or raised particles in the gas stream, $\mathrm{O}_{2}$ transport to the external surface of the particle is several times higher than for a char bed placed in the crucible in the thermogravimetric analyser. For the char used in the study, the diffusion regime could not appear at temperatures below $800{ }^{\circ} \mathrm{C}$. Therefore, the results of the experiments in the temperature range above $600-700{ }^{\circ} \mathrm{C}$, i.e. where the $\mathrm{O}_{2}$ transport rate in the crucible is a key process for determining the oxy-combustion reaction rate, do not reflect the boiler conditions. On the other hand, the $\mathrm{O}_{2}$ transport rate in the thermogravimetric crucible indicates the magnitude of this influence during the analysis itself. Figure 7 also shows the results of studies presented in the literature, which were performed in research devices other than the thermobalance. Figure 7 shows results from following papers:

- Saastamoinen et al. [22] who investigated the combustion of coal dust (obtained from Polish coal) using an $\mathrm{O}_{2} / \mathrm{CO}_{2} / \mathrm{N}_{2}$ mixture in a flow reactor.

- Fennel et al. [23] who investigated coal char combustion in a laboratory fluidised bed reactor.

- Lasek et al. [4] who examined the oxy-combustion of various coal types in a fluidised bed reactor with $0.5 \mathrm{~kg} \mathrm{~h}^{-1}$ capacity.

Table 6 Specific values of char diffusion parameters and dimensionless numbers for both chars

\begin{tabular}{|c|c|c|c|c|c|c|c|c|c|c|}
\hline \multirow[t]{2}{*}{$\mathrm{T} /{ }^{\circ} \mathrm{C}$} & \multicolumn{6}{|l|}{ Lignite char } & \multicolumn{4}{|l|}{ Hard coal char } \\
\hline & $D_{\mathrm{O}_{2}} / \mathrm{m}^{2} \mathrm{~s}^{-1}$ & $S c$ & $D_{\mathrm{K}} / \mathrm{m}^{2} \mathrm{~s}^{-1}$ & $D_{\mathrm{p}} / \mathrm{m}^{2} \mathrm{~s}^{-1}$ & $R e_{\mathrm{p}}$ & $S h$ & $D_{\mathrm{K}} / \mathrm{m}^{2} \mathrm{~s}^{-1}$ & $D_{\mathrm{p}} / \mathrm{m}^{2} \mathrm{~s}^{-1}$ & $R e_{\mathrm{p}}$ & $S h$ \\
\hline 450 & $1.04 \times 10^{4}$ & 0.617 & $4.30 \times 10^{-6}$ & $4.17 \times 10^{-6}$ & 29.1 & 4.76 & $6.49 \times 10^{-6}$ & $6.21 \times 10^{-6}$ & 17.0 & 4.11 \\
\hline 500 & $1.16 \times 10^{4}$ & 0.617 & $4.40 \times 10^{-6}$ & $4.28 \times 10^{-6}$ & 26.0 & 4.61 & $6.64 \times 10^{-6}$ & $6.37 \times 10^{-6}$ & 15.2 & 3.99 \\
\hline 550 & $1.30 \times 10^{4}$ & 0.616 & $4.50 \times 10^{-6}$ & $4.38 \times 10^{-6}$ & 23.3 & 4.46 & $6.79 \times 10^{-6}$ & $6.53 \times 10^{-6}$ & 13.6 & 3.88 \\
\hline 600 & $1.44 \times 10^{4}$ & 0.615 & $4.59 \times 10^{-6}$ & $4.48 \times 10^{-6}$ & 21.1 & 4.34 & $6.94 \times 10^{-6}$ & $6.69 \times 10^{-6}$ & 12.3 & 3.79 \\
\hline 700 & $1.74 \times 10^{4}$ & 0.611 & $4.78 \times 10^{-6}$ & $4.68 \times 10^{-6}$ & 17.5 & 4.13 & $7.22 \times 10^{-6}$ & $6.98 \times 10^{-6}$ & 10.2 & 3.63 \\
\hline 800 & $2.07 \times 10^{4}$ & 0.608 & $4.96 \times 10^{-6}$ & $4.86 \times 10^{-6}$ & 14.9 & 3.96 & $7.50 \times 10^{-6}$ & $7.27 \times 10^{-6}$ & 8.7 & 3.50 \\
\hline 900 & $2.41 \times 10^{4}$ & 0.603 & $5.14 \times 10^{-6}$ & $5.04 \times 10^{-6}$ & 12.8 & 3.82 & $7.76 \times 10^{-6}$ & $7.54 \times 10^{-6}$ & 7.5 & 3.39 \\
\hline 1000 & $2.79 \times 10^{4}$ & 0.599 & $5.31 \times 10^{-6}$ & $5.22 \times 10^{-6}$ & 11.1 & 3.69 & $8.02 \times 10^{-6}$ & $7.81 \times 10^{-6}$ & 6.5 & 3.29 \\
\hline
\end{tabular}


Fig. 7 Comparison of the reaction rate as a function of inverse temperature for coal char oxy-combustion $\left(20 \% \mathrm{O}_{2} /\right.$ $\mathrm{CO}_{2}, 0.1 \mathrm{MPa}$, particle size $172 \mu \mathrm{m})$

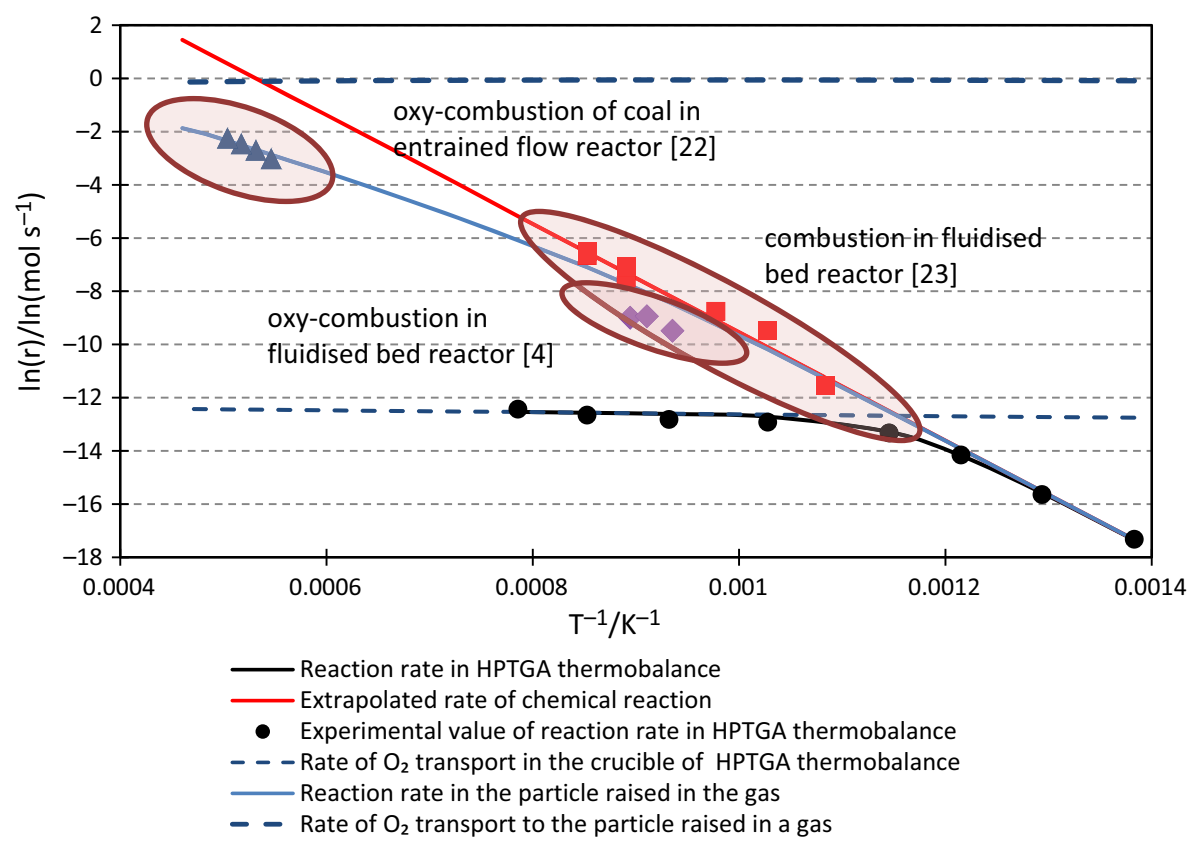

A comparison of results both from this study and from the literature indicates that in thermogravimeter the mass transport rate is much lower than in a fluidised bed which is resulting from the type and dimensions of the TG's crucible. The kinetic parameters of oxy-combustion such as an activation energy, a pre-exponential factor and a reaction rate with respect to the oxygen concentration should be determined in the low-temperature range. Usually, it should be below approximately $600{ }^{\circ} \mathrm{C}$ for oxy-combustion, while the reaction rate at temperatures above $800{ }^{\circ} \mathrm{C}$ should be determined by extrapolation based on the Arrhenius equation. The practical result of the work, which is crucial for its scientific interpretation, is that diffusion effects are essential for the rate-determining step the combustion reaction under standard laboratory conditions where TG is used. Furthermore, they are also important in real devices for coal combustion such as fluidised bed boilers. It should be pointed out that the diffusion limitation in TGA is not the same as that observed in the raised particles in a fluidised bed and in industrial boilers.

In the kinetic analysis for the application of TG, one must be extremely careful during interpretation of the obtained raw results from TG. Summarizing, the TG analysis is very useful for the development of a global model. The reaction rate in the chemical kinetics regime is independent of the apparatus in which the measurement is carried out. However, each type of laboratory equipment, such as a thermobalance, has its construction limitations and differences in reaction rates are observed. Any differences in the reaction rates depending on the apparatus used are due to the presence of reactant gases transportation and the type of gas-solid contact during the analysis.
The proposed oxy-combustion reaction models in TGAs were described in this paper by Eq. (9) for APTGA and by Eq. (21) for HPTGA. They allow estimation of the impact of $\mathrm{O}_{2}$ transportation on the reaction rate which is observed in the apparatus. Furthermore, knowledge of this impact allows both selections of the particular temperature range where the influence of $\mathrm{O}_{2}$ transport is significantly reduced and also the range where it is possible to determine the kinetic parameters for the given chemical reaction. Therefore, as a result, reaction rates for industrial boilers can be determined by extrapolating the kinetic data using the Arrhenius equation.

\section{Conclusions}

Two different arrangements of gas-solid contact in TGA were investigated for the development of a global reaction rate model of coal char oxy-combustion which explains the differences in testing methods. The reason is that the observed effect is related to the gas-solid phase contact, which is associated with crucible dimensions and the direction of the gas flow. The TGA testing device significantly influences the experimental results presented in this paper.

The proposed model combines chemical reactions and mass transfer kinetics of reagents to the reactive surface of the particle and allows different data to be explained. The kinetics of the chemical reaction is independent of the apparatus, which gives the same model of chemical reaction kinetics based on the Arrhenius equation for all the global models. However, different devices have their own transport limitations which result in specific mass transport 
models, e.g. Eq. (9) for APTGA, Eq. (21) for HPTGA and Eq. (22) for a fluidised bed.

The developed model can be used for oxy-combustion process scaling-up purposes, by applying the global model with chemical kinetics and the mass transfer model for a fluidised bed boiler.

Acknowledgements This scientific work was supported by the National Centre for Research and Development, as Strategic Project PS/E/2/66420/10 "Advanced Technologies for Energy Generation: Oxy-combustion technology for PC and $\mathrm{FBC}$ boilers with $\mathrm{CO}_{2}$ capture". The support is gratefully acknowledged. This work was partially financed from the People Programme (Marie Curie Actions) of the European Union's Seventh Framework Programme FP7/ 2007-2013 under REA Grant Agreement No. PIRSES-GA-2013612699 entitled "Long-term research activities in the area of advanced $\mathrm{CO}_{2}$ capture technologies for Clean Coal Energy Generation- "CO2TRIP and by the Polish Ministry of Higher Education and Science, Decision No. 3111/7.PR/2014/2 as "Scientific work financed from the funds for science in years 2014-2017, allocated for completion of the international co-financed project", and also from subsidy project 11.17 .005 .

Open Access This article is distributed under the terms of the Creative Commons Attribution 4.0 International License (http://creative commons.org/licenses/by/4.0/), which permits unrestricted use, distribution, and reproduction in any medium, provided you give appropriate credit to the original author(s) and the source, provide a link to the Creative Commons license, and indicate if changes were made.

\section{References}

1. Stroemberg L. Combustion in a $\mathrm{CO}_{2} / \mathrm{O}_{2}$ mixture for a $\mathrm{CO}_{2}$ emission free process. In: 2nd Nordic mini symposium on carbon dioxide capture and storage, Göteborg, 26 Oct 2001.

2. Buhre BJP, Elliot LK, Sheng CD, Gupta RP, Wall TF. Oxy-fuel combustion technology for coal-fired power generation. Prog Energy Combust Sci. 2005;31:283-307. https://doi.org/10.1016/j. pecs.2005.07.001.

3. Lasek J, Glod K, Janusz M, Kazalski K, Zuwala J. Pressurized oxy-fuel combustion: a Study of selected parameters. Energy Fuels. 2012;26:6492-9. https://doi.org/10.1021/ef201677f.

4. Lasek J, Janusz M, Zuwala J, Glod K, Iluk A. Oxy-fuel combustion of selected solid fuels under atmospheric and elevated pressures. Energy. 2013;62:105-12. https://doi.org/10.1016/j. energy.2013.04.079.

5. Ma L, Mitchell R. Modeling char oxidation behavior under zone II burning conditions at elevated pressures. Combust Flame. 2009;156:37-50. https://doi.org/10.1016/j.combustflame.2008. 06.015 .

6. Roberts DG. Intrinsic reaction kinetics of coal chars with oxygen, carbon dioxide and steam at elevated pressures. Ph.D. thesis, University of Newcastle; 2000.

7. Kordylewski W. Fuel combustion. Wrocław: Publishing House, Oficyna Wydawnicza Politechniki Wrocławskiej; 2008. In Polish.

8. Wall TF, Liu Y, Spero Ch, Elliott L, Khare S, Rathnam R, Zeenathal F, Moghtaderi B, Buhre B, Sheng Ch, Gupta R, Yamada T, Makino K, Yu J. An overview on oxyfuel coal combustion: state of the art research and technology development. Chem Eng Res Des. 2009;87:1003-16. https://doi.org/10. 1016/j.cherd.2009.02.005.
9. Smith IW. The combustion rates of coal chars: a review. 19th symposium on combustion. Proc Combust Inst. 1982;19: 1045-65.

10. Czakiert T, Bis Z, Muskala W, Nowak W. Fuel conversion from oxy-fuel combustion in a circulating fluidized bed. Fuel Process Technol. 2006;87:531-8. https://doi.org/10.1016/j.fuproc.2005. 12.003 .

11. Gomez-Barea A, Ollero P, Arjona R. Reaction-diffusion model of TGA gasification experiments for estimating diffusional effects. Fuel. 2005;84:1695-704. https://doi.org/10.1016/j.fuel.2005.02. 003.

12. Salvador S, Commandre JM, Stanmore BR. Reaction rates for the oxidation of highly sulphurised petroleum cokes: the influence of thermogravimetric conditions and some coke properties. Fuel. 2003;82:715-20. https://doi.org/10.1016/S0016-2361(02)00363-0.

13. Babiński P, Łabojko G, Plis A, Kotyczka-Morańska M. Kinetics of coal and char oxy-combustion studied by TG-FTIR. J Therm Anal Calorim. 2013;113:371-8. https://doi.org/10.1007/s10973013-3002-x.

14. Babiński P, Tomaszewicz M, Topolnicka T, Ściążko M, Zuwała J. Tlenowe spalanie węgla: badania kinetyki i mechanizmu spalania ciśnieniowego. Przem Chem. 2015;94:450-6. https://doi. org/10.15199/62.2015.4.2. (In Polish).

15. Ksepko E, Babinski P, Nalbandian L. The redox reaction kinetics of Sinai ore for chemical looping combustion applications. Appl Energy. 2017;190:1258-74. https://doi.org/10.1016/j.apenergy. 2017.01.026.

16. Ksepko E, Babinski P, Evdou A, Nalbandian L. Studies on the redox reaction kinetics of selected, naturally occurring oxygen carrier. J Therm Anal Calorim. 2015;124:137-50. https://doi.org/ 10.1007/s10973-015-5107-x.

17. Vyazovkin S, Burnham AK, Criado JM, Pérez-Maqueda LA, Popescu C, Sbirrazzuoli N. ICTAC Kinetics Committee recommendations for performing kinetic computations on thermal analysis data. Thermochim Acta. 2011;520:1-19. https://doi.org/ 10.1016/j.tca.2011.03.034.

18. Schulze S, Nikrtiuk P, Abosteif Z, Guhl S, Richter A, Meyer B. Heat and mass transfer within thermogravimetric analyser: from simulation to improved estimation of kinetic data for char gasification. Fuel. 2017;187:338-48. https://doi.org/10.1016/j.fuel. 2016.09.048.

19. De La Cuesta D, Gomez MA, Porteiro J, Febrero L, Granada E, Aree E. CFD analysis of a TG-DSC apparatus application to the indium heating and phase change process. J Therm Anal Calorim. 2014;118:641-50. https://doi.org/10.1007/s10973-014-3734-2.

20. Ollero P, Serrera A, Arjona R, Alcantarilla S. Diffusional effects in TGA gasification experiments for kinetic determination. Fuel. 2002;81:1989-2000. https://doi.org/10.1016/S0016-2361(02)001 26-6.

21. Hottel HC, Noble JJ, Sarofim AF, Silcox GD, Wankat PC, Knaebel KS. Perry's chemical engineering handbook, Section 5 heat and mass transfer. 8th ed. New York: The McGraw-Hill Companies; 2007.

22. Saastamoinen JJ, Aho MJ, Hamalainen JP, Hernberg R, Joutsenoja T. Pressurized pulverized fuel combustion in different concentrations of oxygen and carbon dioxide. Energy Fuels. 1996;10:121-33. https://doi.org/10.1021/ef9501071.

23. Fennel PS, Dennis JS, Hayhurst AN. The order with respect to oxygen and the activation energy for the burning of an anthracitic char in $\mathrm{O}_{2}$ in a fluidised bed, as measured using a rapid analyser for $\mathrm{CO}$ and $\mathrm{CO}_{2}$. Proc Combust Inst. 2009;32:2051-8. https://doi. org/10.1016/j.proci.2008.06.097. 